Check for updates

Cite this: RSC Adv., 2018, 8, 37472

Received 8th October 2018

Accepted 30th October 2018

DOI: $10.1039 / c 8 r a 08302 a$

rsc.li/rsc-advances

\section{Nanostructured thin lignin-derived carbon sheets as excellent reinforcement fillers in polypropylene f}

\author{
Fenggui Chen, (D) *a Wenbing Shi, ${ }^{a}$ Dan Zhou, ${ }^{\text {b }}$ Qinqin Zhang, ${ }^{a}$ Liping LV, ${ }^{a}$ \\ Jiaotong Sun ${ }^{\star b}$ and Liping Yang ${ }^{c}$
}

In this article, natural alkali lignin was freeze-dried and then annealed at different temperatures to achieve lignin-derived carbons (LCs) with mesh-shape or sheet-like morphology, which were incorporated into polypropylene (PP) matrix by melt compounding. Owing to the significantly increased interfacial area and improved dispersion of the carbons in the polymer matrices, with the addition of only $2 \mathrm{wt} \%$ relatively low temperature annealed freeze-dried lignin-derived carbon (FD-LC), the obtained PP/LC composites show notably enhanced tensile mechanical properties, including markedly improved Young's modulus and remarkably increased elongation at break compared with those of neat PP. The enhancements brought by the nano-structured thin FD-LC sheets are far more impressive than that with the same loading of particulate as-received lignin-derived carbon (AR-LC). The FD-LC filled PP composites also have rough fractured surfaces with fiber pull-out near the interface, revealing the non-negligible toughening effect of the LC. In addition, the higher temperature annealed FD-LC filler induces the further reinforcement of the composites. For the FD-LC annealed at $900{ }^{\circ} \mathrm{C}$, the corresponding composite possesses the highest Young's modulus of $668 \mathrm{MPa}$.

\section{Introduction}

Lignin is a natural macromolecular material, which accounts for nearly $30 \%$ of the organic carbon on earth, second only to cellulose. ${ }^{1,2}$ As a main by-product from the paper production industry, lignin is readily available at low cost, with an annual world production volume up to 50 million tons as reported, however, it is scarcely utilised and usually poured into the environment directly. ${ }^{3,4}$ Currently lignin is mainly burned as fuel, giving it a very low value. Since lignin is one of the few renewable sources of aromatic macromolecules and possesses rich phenolic and aliphatic hydroxyl groups, enormous efforts have been devoted to the development of value-added applications for lignin..$^{5-7}$ For example, lignin can be used as an excellent adsorbent for heavy metal ions and organic pollutants over wide concentration ranges owing to its abundant phenolic groups. ${ }^{8,9}$ It has also been widely reported that lignin can be

${ }^{a}$ School of Chemistry and Chemical Engineering, Yangtze Normal University, Fuling, Chongqing 408100, China. E-mail: fgchen@yznu.cn

${ }^{b}$ School of Materials Science and Engineering, Yangtze Normal University, Fuling, Chongqing 408100, China. E-mail: jiaotongsun@outlook.com

${ }^{c}$ Guangdong Gulf New Materials Research Institute, Shenzhen 518000, Guangdong, China

$\dagger$ Electronic supplementary information (ESI) available: SEM image of as-received and freeze-dried lignin, BET SSA and BJH pore volume results of lignin and the corresponding LCs, DSC of PP/LC composites are included. See DOI: 10.1039/c8ra08302a introduced into thermoplastic polymers as reinforcing or toughening agents. ${ }^{10-14}$

Particularly, lignin is also used as a precursor to prepare carbon-based materials, such as activated carbons, ${ }^{15,16}$ carbon fibers, ${ }^{17-19}$ carbon nanotubes (CNTs),${ }^{20}$ and carbon aerogels. ${ }^{21}$ On the other hand, several kinds of carbons are usually incorporated into polymers to enhance their mechanical or other functional properties. ${ }^{22,23}$ However, the inorganic carbons show poor compatibility with polymers, resulting in their poor and un-uniform dispersion in the polymer matrix. To address this issue, recently greater efforts have been devoted to improving the dispersion of carbon filler in polymer matrix via physical

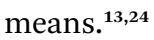

Freeze-drying (FD) method has been widely used to prepare highly porous materials, such as carbon and polymer aerogels. ${ }^{25-28}$ In the FD step, the sublimation of the ice crystals leads to a highly porous material with high specific surface area (SSA). Therefore, alkali lignin with three-dimensionally branched macromolecular structure after FD exhibits smaller lignin particles in the form of sheets, which significantly increases its interfacial area and improves the dispersion in non-polar polyolefin, and therefore drastically enhances the reinforcing and antioxidant effect of lignin. ${ }^{29}$ On this base, it was highly hypothesized that the sheet-like freeze-dried lignin may keep its morphology after carbonization. In this connection, the reduced size and increased aspect ratio of the LC particles may greatly facilitate the dispersion of LCs in polymers by melt 
compounding, while the high SSA of the LC sheets would provide larger interfacial area, benefiting the functions of LCs as reinforcement/toughening agents. ${ }^{30}$

Herein, to verify the hypothesis, alkali lignin was first freezedried to achieve a nano-size thin sheet with high surface area, then applied as carbon precursors and carbonized into FD-LCs, which were subsequently incorporated into polypropylene (PP) matrix. Our results show that the enlarged interfacial area between LCs and PP induces a drastically improved dispersion of the inorganic filler in PP matrix, impressively, which not only enhances reinforcing effect of the LCs in PP, but also enables us to demonstrate the great potential of LC as a toughening agent in PP. It is meaningful to develop these value-added applications for the low cost lignin.

\section{Experimental section}

\subsection{Materials}

Water soluble alkali lignin (AL) was purchased from TCI America (the product number is L0082) and used as received. PP (Cosmoplene H101E) was supplied by Polyolefin Incorporated Company (Singapore). All other chemicals were purchased from Sigma-Aldrich Chemicals Incorporation and used without further purification. All aqueous solutions were prepared using deionized (DI) water with a resistivity of $18.2 \mathrm{M} \Omega \mathrm{cm}$, purified by filtration through Millipore Gradient system after distillation.

\subsection{Preparation of lignin-derived carbon (LC)}

Alkali lignin was dissolved in DI water by ultrasonic processing in an ultrasonic bath to purchase aqueous solutions with concentrations of 100 and $10 \mathrm{mg} \mathrm{mL}^{-1}$, which were freezed at $-196{ }^{\circ} \mathrm{C}$ using liquid $\mathrm{N}_{2}$, and then freeze-dried in vacuum for 3 days. And lignin aerogels with different densities were obtained.

Afterwards, the as-received lignin and the obtained porous lignin aerogels were placed in ceramic ships in a tube furnace (VTF 50/15-L, Entech, Sweden) and annealed in Ar atmosphere based on the following temperature program: heated at a rate of $5{ }^{\circ} \mathrm{C} \mathrm{min} \mathrm{min}^{-1}$ to $250{ }^{\circ} \mathrm{C}$, held for $30 \mathrm{~min}$, heated at a rate of $3{ }^{\circ} \mathrm{C} \min ^{-1}$ to a determined temperature, and held for $60 \mathrm{~min}$. The products were then collected after cooling to room temperature.

\subsection{Preparation of $P P / L C$ composites}

Respectively, a certain amount of as-received (AR-LC) and freeze-dried lignin-derived carbons (FD-LC) were mixed with PP pellets by melt compounding using a Hakke MiniLab twin screw micro extruder (Germany) at $195{ }^{\circ} \mathrm{C}$. Prior to the compounding, the PP pellets were dried in a vacuum oven at $50{ }^{\circ} \mathrm{C}$ for 12 hours.

\subsection{Characterization}

The morphologies of the lignin and annealed LC samples were examined using a field emission scanning electron microscope (FESEM, JEOL JSM 6340F) after gold sputtering, which was also applied to see the fractured surface of neat PP and PP/LC composite samples. An Olympus BX53 polarizing optical microscope (POM) was employed to observe the dispersion state of LC filler in PP matrix at a magnification of $\times 100$. The Brunauer-Emmett-Teller (BET) specific surface areas of the carbon fillers were determined by nitrogen adsorption measurements using a Tristar-3000 surface area analyser. The tensile mechanical properties of the composites were measured using an Instron 5567 machine according to ISO standard 527 at

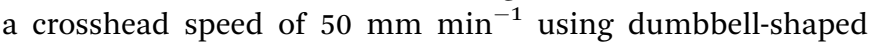
specimens (ISO 527-2-Typer 5A, $500 \mathrm{~N}$ load cell), which were prepared using a Thermo Hakke microinjector (Germany) at $210^{\circ} \mathrm{C}$ with a pressure of 800 bar, and more than six specimens were tested for each set of variation. Fourier transform infrared spectroscopic (FTIR) measurements were performed using a Perkin-Elmer Instruments Spectrum GX FTIR spectrometer from 500 to $4000 \mathrm{~cm}^{-1}$ by scanning 16 times at a resolution of $4 \mathrm{~cm}^{-1}$. Thermo-gravimetric analysis (TGA) was conducted to define its degradation temperature $\left(T_{\mathrm{d}}\right)$ as the temperature at $50 \mathrm{wt} \%$ weight loss by using a TA Q500 analyser at a heating rate of $10{ }^{\circ} \mathrm{C} \mathrm{min}^{-1}$ from room temperature to $650{ }^{\circ} \mathrm{C}$ in air. Differential scanning calorimetry (DSC) was recorded on a TA Instruments DSC Q10 using $\mathrm{N}_{2}$ as purge gas at heating and cooling rates of $10{ }^{\circ} \mathrm{C} \mathrm{min}^{-1}$.

\section{Results and discussion}

\subsection{Preparation of FD-LC filler with different concentrations of lignin at different carbonization temperatures}

As reported, lignin consists of rigid aromatic macromolecules, and it is recognized as an abundant and lost cost natural carbon resource. Besides, FD of the three-dimensionally branched macromolecular alkali lignin will lead to generation of a highly porous sheet-like material with high specific surface area (SSA). That is, FD plays great role on morphology of the obtained lignin. The total volume of the lignin bulk structure at a certain concentration would not shrink in the FD process, it is also hypothesized here that the obtained lignin precursors may maintain their morphologies after the carbonization. In this connection, the freeze-drying process may finally achieve the carbon with desired morphology. Thus, alkali lignin aqueous solutions with different concentration were freeze-dried, and subsequent annealed at different temperature into different carbons. The SEM images of lignin-derived carbons (LCs) annealed at $600{ }^{\circ} \mathrm{C}$ can be seen in Fig. 1. As shown, the asreceived lignin-derived carbon (AR-LC) consists of large spherical shaped particles with sizes up to tens of microns as the corresponding lignin precursor (Fig. 1a; and SEM images of lignin are shown in Fig. S1†). ${ }^{29}$ By contrast, the freeze-dried lignin derived carbon (FD-LC) samples exhibit a threedimensional mesh-shaped or sheet-like morphology (Fig. 1b and c) with nanometer thickness as freeze-dried lignin, implying that the carbonization did not change the whole morphology of lignin precursor. On the other hand, the thickness of lignin decreases with the reduction of lignin concentration, when it also becomes thinner after carbonization compared with the lignin precursors. As clearly shown in Fig. 1b and $\mathrm{c}$ inset, the typical thickness of FD-LC is reduced to $\sim 800 \mathrm{~nm}$ with lignin concentration of $100 \mathrm{mg} \mathrm{mL}^{-1}$, and it is 


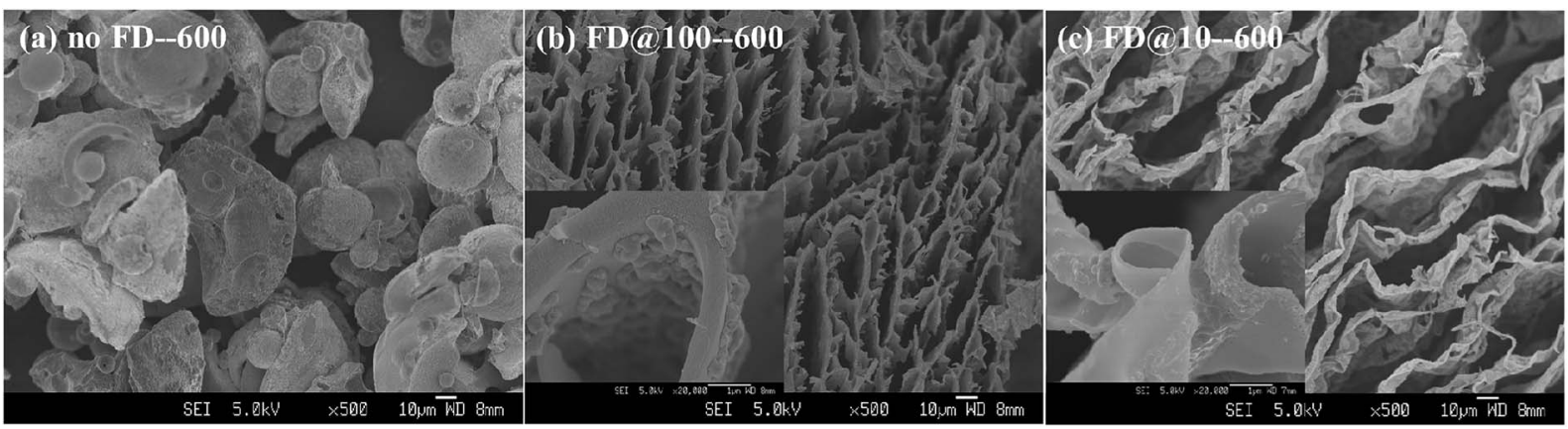

Fig. 1 SEM images of AR-LC (a), FD-LC at lignin concentration of $100 \mathrm{mg} \mathrm{mL}^{-1}$ (b) and $10 \mathrm{mg} \mathrm{mL}^{-1}$ (c), which are all carbonized at $600{ }^{\circ} \mathrm{C}$ (inset scale bar: $1 \mu \mathrm{m})$.

further reduced to $\sim 50 \mathrm{~nm}$ with lignin concentration of $10 \mathrm{mg}$ $\mathrm{mL}^{-1}$.

Obviously, such thin FD-LC sheets have larger SSA than the AR-LC, as shown by their BET $\mathrm{N}_{2}$-adsorption isotherms in Fig. 2a and BET analysis results in Table S1. $\dagger$ The as-received lignin even exhibits no value of SSA, and the freeze-drying method gives it rise to $4.0 \mathrm{~m}^{2} \mathrm{~g}^{-1}$. Besides, the annealing process also increases the SSA, the corresponding SSA increases with the carbonization temperature rises. For instance, the FDLC annealed at $600{ }^{\circ} \mathrm{C}$ has a SSA of $143 \mathrm{~m}^{2} \mathrm{~g}^{-1}$, while the SSA reaches to $202 \mathrm{~m}^{2} \mathrm{~g}^{-1}$ at the annealing temperature of $900{ }^{\circ} \mathrm{C}$. These leave a porous morphology behind, at the same time, it compromises the structural integrity of the particles. Thus, the initial lignin concentration dominates the density and morphology of the obtained lignin precursors and the corresponding FD-LCs. With the reduced lignin concentration, much thinner sheet-like LC particles with larger pores are formed. Furthermore, other than the concentration, the annealing temperature also affects the morphology and component of the LC fillers, lignin precursors were annealed at different temperature for preparation of LCs. The FTIR data in Fig. $2 \mathrm{~b}$ shows that as annealing temperature increases, the broad bands at $\sim 3430 \mathrm{~cm}^{-1}$ and $\sim 1592 \mathrm{~cm}^{-1}$ corresponding to phenolic hydroxyl group and aromatic group, respectively, decrease, indicating a reduction of functional groups at higher annealing temperatures. More functional groups are left under the lower annealing temperature, and the increase of the annealing temperature also decreases the product yield drastically, indicating an increase in the degree of carbonization. ${ }^{31}$

\subsection{The dispersion state of $\mathrm{LC}$ filler in PP matrix}

The performance of polymer composites strongly depends on the dispersion state of the fillers in the polymer matrices. For instance, a better dispersion may result in improved interactions between the polymers and fillers. And the mechanical properties of the composites may thereby be enhanced owing to the more effective stress transferred from the matrices to fillers. ${ }^{32}$ To investigate the dispersion state of the FD-LC in PP, the AR-LC and FD-LC were respectively incorporated into PP, via melt compounding under the same conditions for comparison. The POM images in Fig. 3 a show that the sizes and shapes of the AR-LC particles (the dark regions) are almost not changed after the melt compounding, with sizes of tens of microns. By contrast, these spherical or irregular shaped large particles disappear in the FD-LCs blended PP composites, and many
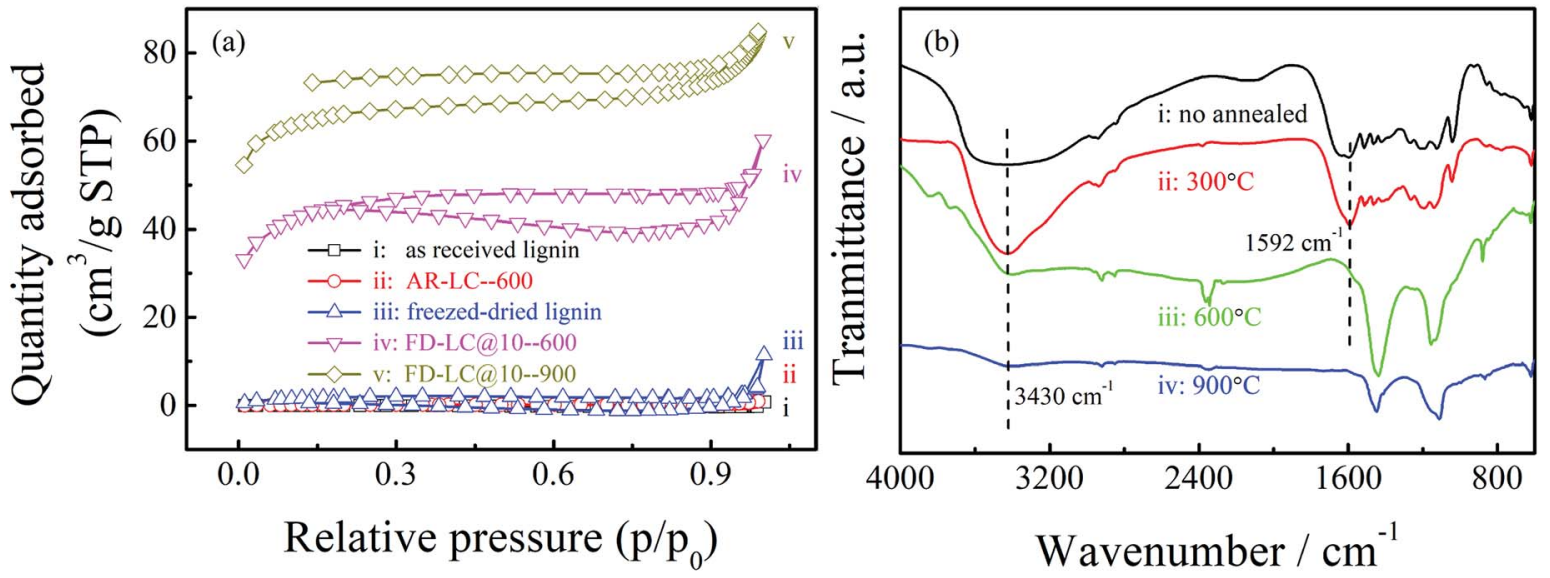

Fig. 2 (a) $\mathrm{N}_{2}$-adsorption isotherms of as-received lignin (i), $A R-L C$ annealed at $600{ }^{\circ} \mathrm{C}$ (ii), freeze-dried lignin from $10 \mathrm{mg} \mathrm{mL}{ }^{-1}$ solutions (iii), and FD-LCs from $10 \mathrm{mg} \mathrm{mL}^{-1}$ lignin aqueous solutions and respectively annealed at 600 (iv) and $900^{\circ} \mathrm{C}$ (v). (b) FTIR spectra of as-received lignin (i), and LCs respectively prepared by annealing at 300 (ii), 600 (iii), and $900{ }^{\circ} \mathrm{C}$ (iv). 

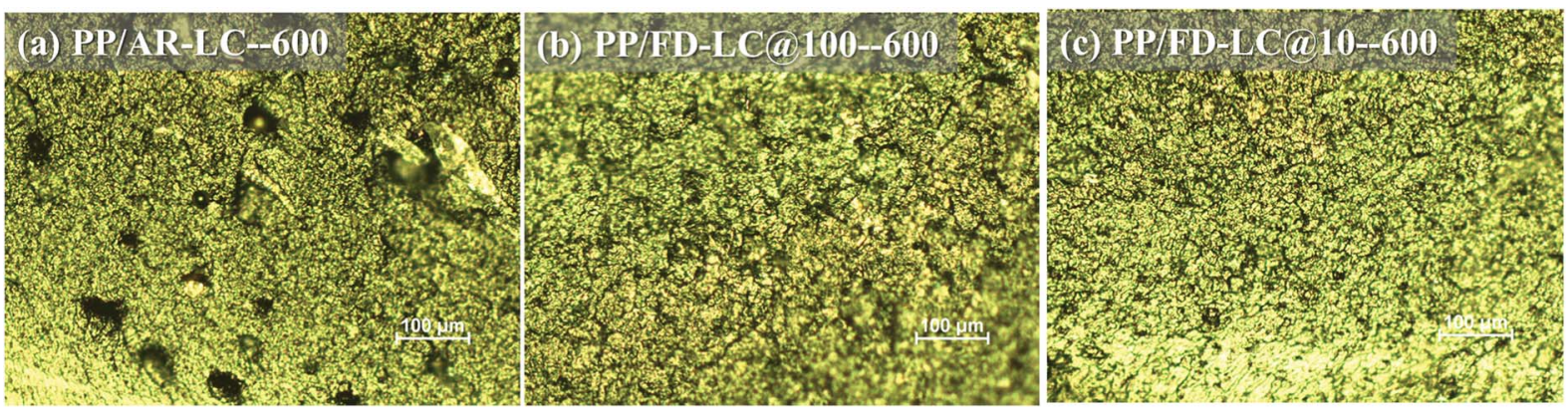

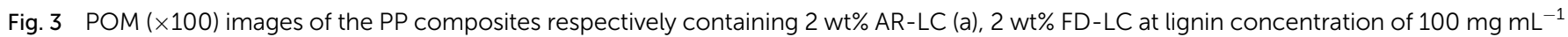
(b) and $10 \mathrm{mg} \mathrm{mL}^{-1}$ (c). LCs are all carbonized at $600^{\circ} \mathrm{C}$.

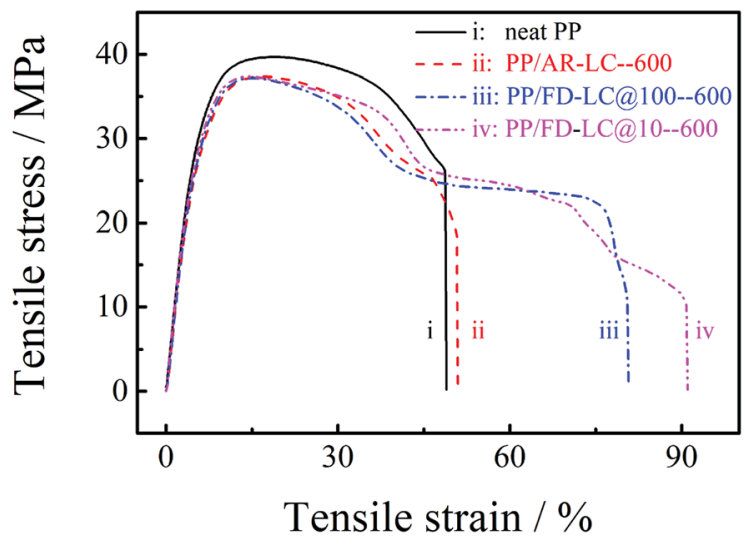

Fig. 4 Tensile stress-strain curves of neat PP (i), and the PP/LC composites containing 2 wt\% AR-LC (ii), FD-LC from the aqueous dispersions with lignin concentration of $100 \mathrm{mg} \mathrm{mL}^{-1}$ (iii), and FD-LC from the aqueous dispersions with lignin concentration of $10 \mathrm{mg} \mathrm{mL}^{-1}$ (iv). LCs are all carbonized at $600^{\circ} \mathrm{C}$.

short and fine dark lines are observed for the composites of the FD-LC and PP (Fig. 3b and c), implying that the FD-LCs are in the form of small and fine sheets in the PP matrix. Obviously, the thin FD-LC meshes or sheets could be more easily broken down into small pieces than AR-LC particles, facilitating their improved dispersion in the PP matrix. Thus, compared with ARLC, the FD-LC filler with enlarged surface area would provide much larger interfacial area and could be more uniformly and smaller size dispersed in the PP matrix.

\subsection{The effect of freeze-drying process on the mechanical properties of the PP/LC composites}

FD-LCs, exhibiting mesh-shape or sheet-like morphology, can be easily broken down into small pieces during melt compounding process, hence giving the corresponding PP/FD-LC composites more uniform filler dispersion and processing much larger interfacial area than the counterpart with AR-LC. And the improved dispersion may results in the enhanced mechanical properties. To investigate the reinforcing effect of the FD-LC in polyolefin, a series of PP/LCs specimens were prepared for tensile tests. Typical tensile stress-strain curves of neat PP and the PP/LCs samples are presented in Fig. 4. Also, the compositions and preparation conditions for the composites are summarized in Table 1, in which, PP/AR-LC-600 refers to the composite containing $2 \mathrm{wt} \%$ of AR-LC which was annealed at $600{ }^{\circ} \mathrm{C}$, while PP/LC-FD@100-900 represents the composite containing $2 \mathrm{wt} \%$ of FD-LC, which was prepared by carbonization of the freeze-dried lignin precursor with lignin concentration of $100 \mathrm{mg} \mathrm{mL}^{-1}$ at $900{ }^{\circ} \mathrm{C}$, and so on.

From Table 1 and Fig. 5, it is clear that the addition of $600{ }^{\circ} \mathrm{C}$ annealed FD-LCs into PP can increase the tensile modulus, at the same time, the modulus slightly decreases for the AR-LC filled composites. That is, the PP/FD-LCs composites exhibit higher modulus than their counterpart with the same amount of AR-LC, and for the former, as the concentration of lignin precursor used for FD reduces from $100 \mathrm{mg} \mathrm{mL}^{-1}$ to $10 \mathrm{mg}$ $\mathrm{mL}^{-1}$, the resultant FD-LC based PP composite exhibits a further increase of the modulus. Obviously, the harden LCs is able to enhance the tensile modulus of the composite, the

Table 1 Mechanical properties of neat PP and PP composites containing LCs at different lignin concentration, the tensile speed is 50 mm min ${ }^{-1}$

\begin{tabular}{|c|c|c|c|c|c|c|c|}
\hline Neat PP & - & - & 0 & $616 \pm 16$ & $39.1 \pm 0.8$ & $0.177 \pm 0.008$ & $54 \pm 5$ \\
\hline PP/FD-LC@100-600 & 100 & 600 & 2 & $640 \pm 11$ & $37.6 \pm 0.6$ & $0.151 \pm 0.006$ & $77 \pm 18$ \\
\hline PP/FD-LC@10-600 & 10 & 600 & 2 & $650 \pm 40$ & $38.1 \pm 1.4$ & $0.145 \pm 0.006$ & $79 \pm 22$ \\
\hline PP/FD-LC@100-300 & 100 & 300 & 2 & $628 \pm 27$ & $37.9 \pm 0.8$ & $0.156 \pm 0.007$ & $125 \pm 31$ \\
\hline
\end{tabular}

${ }^{a} 2 \mathrm{wt} \%$ LCs in the PP/LCs composites. 


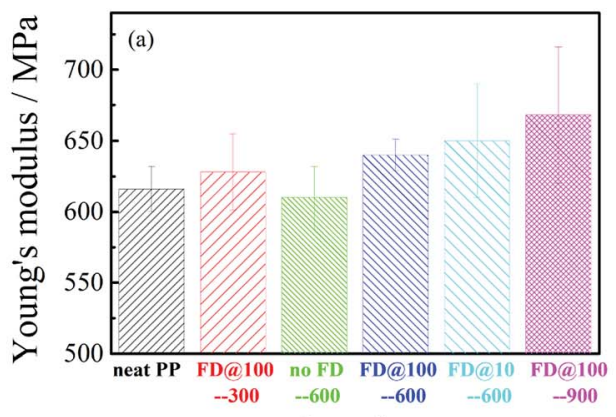

Samples

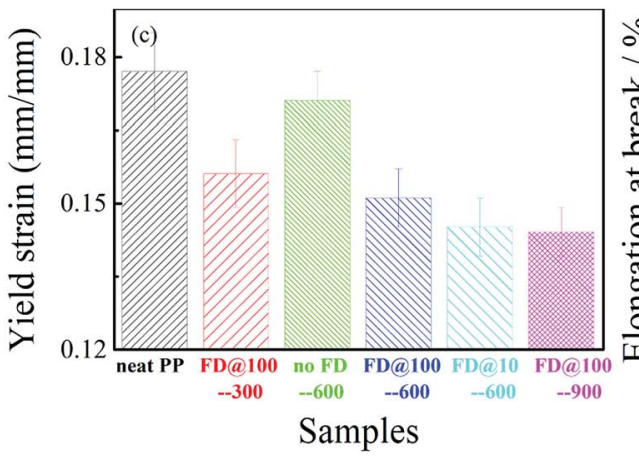

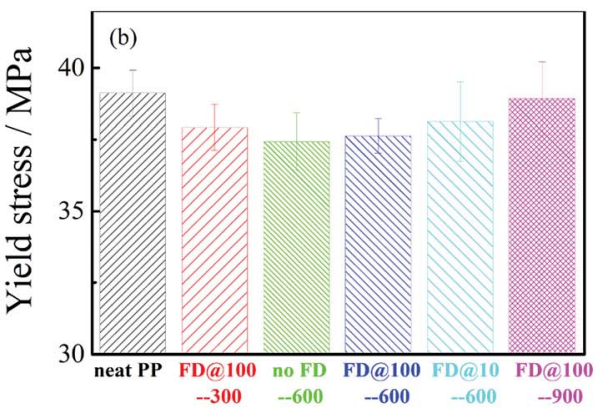

Samples

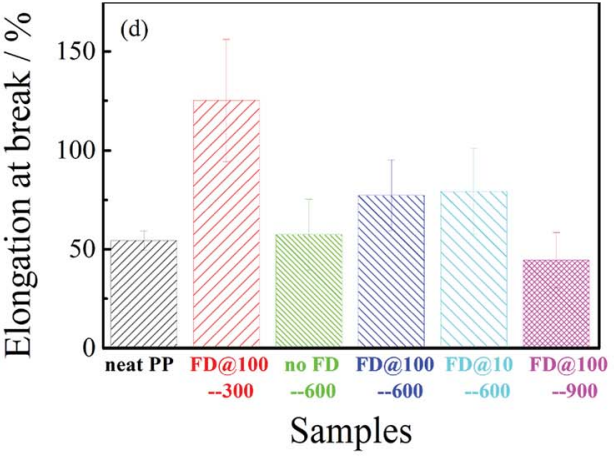

Fig. 5 Tensile mechanical properties of the PP/LCs composites. (a) Young's modulus, (b) yield stress, (c) yield strain and (d) elongation at break of neat PP, PP/LCs composite containing 2 wt\% LCs.

reinforcing effect is also closely related to the SSA of the LC fillers, that is, the enlarged interfacial area of the FD-LC leads to the improved filler-matrix interactions. ${ }^{32}$

Similar to other hard fillers, it is easy to understand that FDLCs also induces a decrease in yield strain, and the decrease is slightly upon the improvement of dispersion state of LCs in the PP matrices. Concretely, PP/LC-FD@100-600 exhibits a much lower yield strain $\left(0.151 \mathrm{~mm} \mathrm{~mm}^{-1}\right)$ than that of neat PP and PP/AR-LC. With further improved dispersion induced by more dilute lignin solution, PP/FD-LC@10-600 has a lowest yield strain of $0.145 \mathrm{~mm} \mathrm{~mm}^{-1}$. Besides, the addition of LCs also induces a slightly drop of yield stress.

Besides, the change in elongation at break brought by the introduction of FD-LCs annealed at $600{ }^{\circ} \mathrm{C}$ is more intriguing, as shown in Table 1 and Fig. 5 . The composite containing $2 \mathrm{wt} \%$ AR-LC (PP/AR-LC-600) exhibits a slight change of the elongation at break with neat PP, by contrast, the addition of FD-LCs with lignin concentration of $100 \mathrm{mg} \mathrm{mL}^{-1}$ and annealed at $600{ }^{\circ} \mathrm{C}$ into PP leads to significantly increased elongation at break from $54 \%$ to $77 \%$. This demonstrates that porous and nanostructured thin sheet morphology of the FD-LCs gives large interfacial area and hence enhances the interactions with the polymer matrix, by which FD-LCs is also able to enhance its toughening effect in the composites. Whereas, without FD process, the much weaker interaction area between polymer and large AR-LC particle leads to a very limited interfacial adhesion, and the elongation at break hence change slightly. Therefore, the morphology of the LC fillers greatly affects their dispersion in the matrix, further playing a great and important role in determining the overall mechanical properties of the composites. ${ }^{33}$ However, it wastes more time and water to achieve the freeze-dried lignin in more dilute aqueous solution, thus, the FD-LCs prepared from $100 \mathrm{mg} \mathrm{mL}^{-1}$ lignin solution are employed as fillers in the following discussion.

The increase of elongation at break implies that FD-LCs at 300 and $600{ }^{\circ} \mathrm{C}$ may act as an effective toughening agent to enhance the toughness of the composites, which can also be demonstrated by different features of the fractured surfaces of the composite specimens. The SEM images in Fig. 6 show the morphologies of the fractured surfaces of neat PP and PP/FD-LC composites. It can be seem that the fracture surface of neat PP (Fig. 6a) is quite smooth except existence of some river-like lines. On the contrast, the FD-LCs blended PP displays a much rougher fractured surface, and the pull-out of fibers can be clearly observed in a high-magnification image for the LC filler at concentration of 100 and $10 \mathrm{mg} \mathrm{mL}^{-1}$ (insets in Fig. 6b and c). ${ }^{34}$

\subsection{The effect of carbonization temperature on the mechanical properties of the composites}

To further investigate the effect of annealing temperature on the LC component and their corresponding reinforcing effect on polymer composites, lignin precursors were annealed at different temperature for preparation of different LC fillers. As discussed above, the increasing annealing temperature results in a significant change in SSA and component of the obtained LCs. Based on the above studies, to reveal the effects of annealing temperature on the properties of composites, the FCs was annealed at various temperatures, respectively namely 900 , 600 and $300{ }^{\circ} \mathrm{C}$, and the corresponding LCs blended PP 

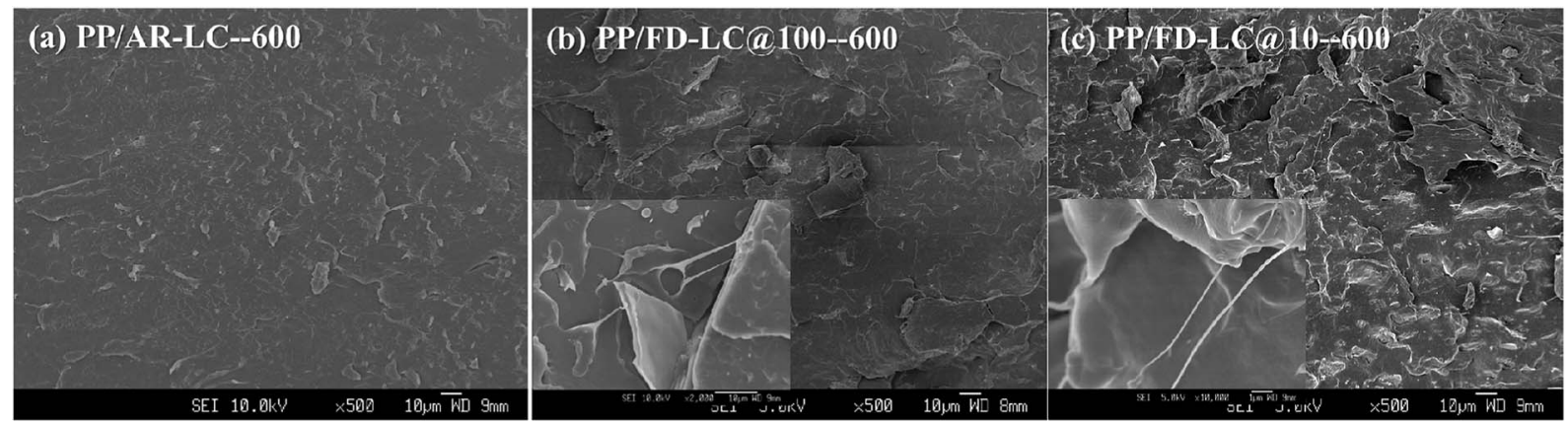

Fig. 6 SEM images showing the fractured surfaces of (a) neat PP, (b) PP/FD-LC@100 $\mathrm{mg} \mathrm{mL}^{-1}$, (c) PP/FD-LC@10 mg mL ${ }^{-1}$; the insets show fiber pulling-out in the regions near LC particles. The filler content is $2 \mathrm{wt} \%$.

composite specimens are prepared. As can be seem in Fig. 5 and 7 , clearly, the addition of LCs annealed at $300{ }^{\circ} \mathrm{C}$ into PP can dramatically increase tensile modulus. Moreover, as the annealing temperature increases, the Young's modulus of the corresponding composite is further enhanced, and the reinforcing effect becomes more prominent. For FD-LC carbonized at $900{ }^{\circ} \mathrm{C}$, its composite exhibits a highest modulus of $668 \mathrm{MPa}$. Besides, the enhanced interaction was induced by the increased SSA, and the change of tensile modulus may also be attributed to that the different annealing temperature generates different LCs, containing different functional groups as the FTIR spectra shown in Fig. 2b. Obviously, the reinforcing effect is closely related to the chemical structure of the LC fillers. Simultaneously, unlike the changes in modulus, the higher temperature annealed LC is more inclined to the drop of yield strain and elongation at break. That is, as annealing temperature increases, the yield strain and the elongation of the corresponding LC incorporated PP composites decreases. For $900{ }^{\circ} \mathrm{C}$ carbonized FD-LC filled composite, it exhibits lowest yield strain of $0.144 \mathrm{~mm} \mathrm{~mm}^{-1}$ and elongation at break of $44 \%$, and the related decrease is slightly upon the improved dispersion state of LC filler in the PP matrix. By contrast, it is quite similar to the lignin precursor blended composite, the addition of FDLC filler annealed at $300{ }^{\circ} \mathrm{C}$ leads to significantly increased

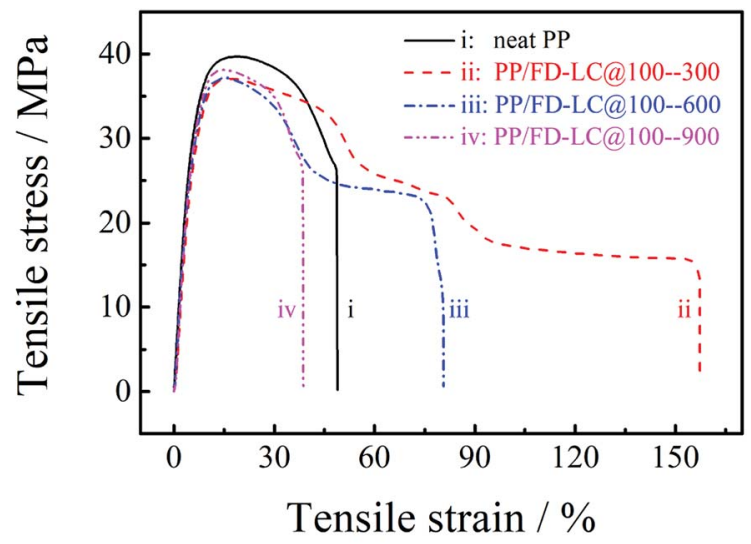

Fig. 7 Tensile stress-strain curves of neat PP (i), and PP composites containing 2 wt\% FD-LCs prepared from freeze-dried lignin with concentration of $100 \mathrm{mg} \mathrm{mL}^{-1}$ and respectively carbonized at 300 (ii), 600 (iii), $900^{\circ} \mathrm{C}$ (iv). elongation at break, which reaches to $125 \%{ }^{29}$ More specifically, the increased SSA of the nano-structured FD-LCs annealed at low temperature improves the dispersion and compatibility of functional group containing FD-LCs in PP. On this base, with the improved interaction of the functional group as carboxyl $(\mathrm{C}=\mathrm{O})$ and the organic polymer chains by forming hydrogen bond, etc. it further enhances the interfacial adhesion between the FD-LC filler and the PP matrix. These interactions can be also confirmed by that the small FD-LC particles do not aggregate severely in the composites. Unlike the organic fillers containing functional group, the van der Waals attractions disappear for the FD-LC filler annealed at rather high temperature, which is fully carbonized. As a result, the extremely inorganic FD-LC blended composites exhibit a slightly larger size of the filler, as can be seem in the POM images in Fig. S4. $\dagger$ Therefore, the morphology and the components of the LC fillers both take great effect in the overall mechanical properties of the composites.

\subsection{Thermal properties of the $\mathrm{PP} / \mathrm{LC}$ composites}

Furthermore, the thermal properties of the PP/LC composites are also investigated to see the influence of LC filler in polyolefin. Table 2 and Fig. 8 show that the addition of AR-LC annealed at $600{ }^{\circ} \mathrm{C}$ lowers the thermal degradation temperature $\left(T_{\mathrm{d}}\right)$ of the composite. It is probably due to the weak interaction between the filler and the matrix material induced by the poor dispersion of carbon filler in PP matrix. On the other hand, with the improved dispersion by the nano-size thin LC sheet, the FD-LCs induces an increase of $T_{\mathrm{d}}$ and a drop of weight losing rate. Specifically, the $T_{\mathrm{d}}$ further increased to $304{ }^{\circ} \mathrm{C}$ for LC obtained from more dilute lignin solution with concentration of $10 \mathrm{mg} \mathrm{mL}^{-1}$. It is understandable that the carbon filler is able to enhance the thermal stability and improves the heat resistance of composites. Besides, TGA thermographs also show that the AR-LC incorporated PP composite exhibits an obvious second step of weight loss, whereas, the FD-LC addition results in almost only one major weight loss of the composites. The second drop at higher temperature in the former one is subjected to that the filled AR-LC particles have poor interaction with PP molecules. Furthermore, the thermal stabilities of the $\mathrm{PP} / \mathrm{LC}$ composites as a function of annealing temperature for fillers are also revealed (Fig. 8b). Clearly, with the increased 
Table 2 Thermal properties of neat PP and PP/LC composites

\begin{tabular}{|c|c|c|c|c|c|c|}
\hline Sample & $T_{\mathrm{d}}\left({ }^{\circ} \mathrm{C}\right)$ & $T_{\mathrm{g}}\left({ }^{\circ} \mathrm{C}\right)$ & $T_{\mathrm{m}}\left({ }^{\circ} \mathrm{C}\right)$ & $\Delta H_{\mathrm{m}}\left(\mathrm{J} \mathrm{g}^{-1}\right)$ & $T_{\mathrm{c}}\left({ }^{\circ} \mathrm{C}\right)$ & $-\Delta H_{\mathrm{c}}\left(\mathrm{J} \mathrm{g}^{-1}\right)$ \\
\hline Neat PP & 339 & -4.6 & 161.8 & 60.8 & 110.9 & 89.6 \\
\hline PP/AR-LC-600 & 330 & -6.4 & 159.0 & 78.2 & 119.1 & 81.6 \\
\hline PP/FD-LC@100-600 & 350 & -6.2 & 159.1 & 80.6 & 119.7 & 81.6 \\
\hline PP/FD-LC@10-600 & 359 & -3.2 & 161.5 & 72.7 & 120.4 & 79.7 \\
\hline PP/FD-LC@100-300 & 343 & -4.5 & 159.7 & 80.5 & 118.2 & 80.6 \\
\hline PP/FD-LC@100-900 & 353 & -8.5 & 159.3 & 80.3 & 120.3 & 81.8 \\
\hline
\end{tabular}
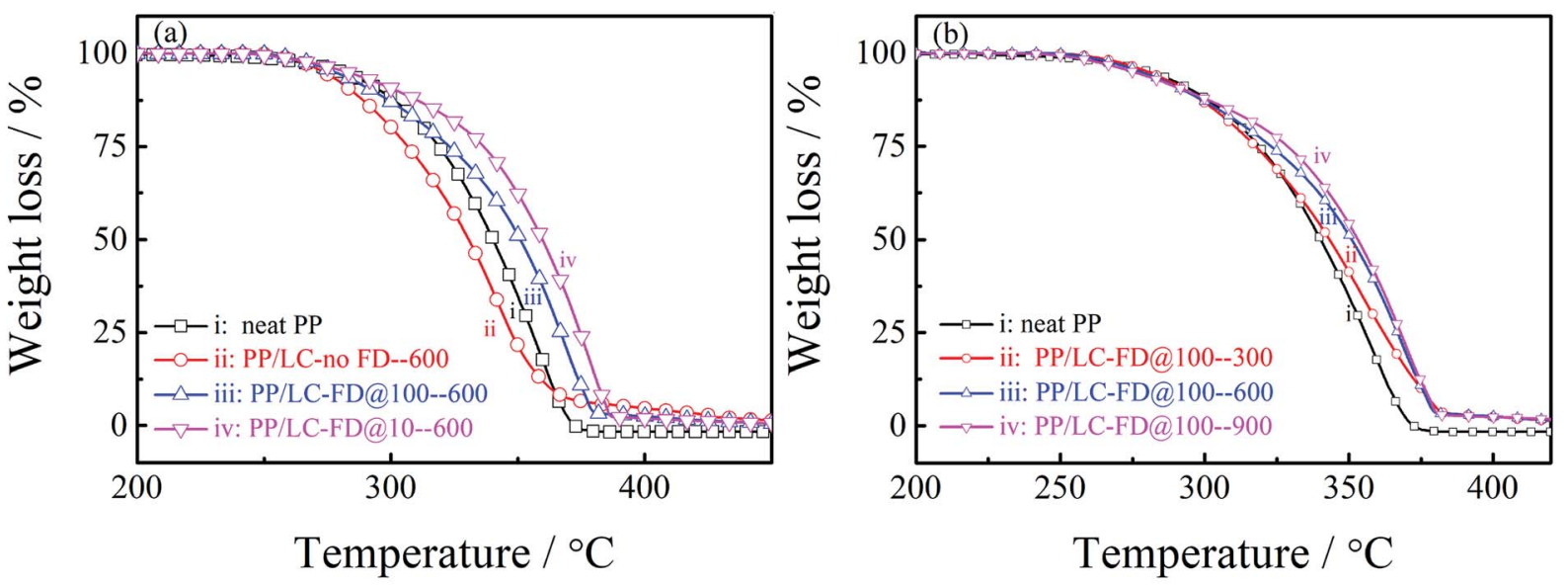

Fig. 8 (a) TGA curves of neat PP (i), and PP based composites containing 2 wt\% AR-LC (ii), FD-LCs at lignin conc. of $100 \mathrm{mg} \mathrm{mL}^{-1}$ (iii), FD-LCs at conc. of $10 \mathrm{mg} \mathrm{mL}^{-1}$ (iv), which all are carbonized at $600^{\circ} \mathrm{C}$. (b) TGA curves of neat PP (i), and PP/LC composites containing 2 wt\% LC at lignin conc. of $100 \mathrm{mg} \mathrm{mL}^{-1}$, which are respectively carbonized at $300^{\circ} \mathrm{C}$ (ii), $600^{\circ} \mathrm{C}$ (iii), $900{ }^{\circ} \mathrm{C}$ (iv).

annealing temperature, the $T_{\mathrm{d}}$ of the composite gradually increases. Similar to other carbons, the LC filler is able to enhance the thermal stability. With more carbonization degrees by higher annealing temperature, the FD-LC possesses higher thermal resistance.

Moreover, from DSC analysis results (Table 2, Fig. S2 and $\mathrm{S} 3 \dagger)$, it is clear that the addition of LCs annealed at $600{ }^{\circ} \mathrm{C}$ decreases the glass transition temperature $\left(T_{\mathrm{g}}\right)$, which is due to the increased chain segmental mobility in PP-LC interphase. In addition, higher temperature annealed FD-LC filler induces more decreases of $T_{\mathrm{g}}$, which is probably due to the increases of interphase by improved SSA at higher carbonization temperature. On one hand, on the heating process in DSC, the peak melting temperatures $\left(T_{\mathrm{m}}\right)$ shows a little decrease. On the other hand, upon cooling process in DSC, the incorporation of LCs into PP leads to an increase of the peak crystallization temperatures $\left(T_{\mathrm{c}}\right)$. In case of PP/AR-LC sample, $T_{\mathrm{c}}$ increases by $\sim 9{ }^{\circ} \mathrm{C}$. And for FD-LCs, it exhibits a slight higher $T_{\mathrm{c}}$ than that of AR-LC. The increase of $T_{\mathrm{c}}$ is mainly ascribed to the nucleating effect of the LCs in PP. ${ }^{35}$ Furthermore, the addition of FD-LCs also slightly further decreases the crystallization enthalpy $\left(\Delta H_{\mathrm{c}}\right)$, indicating that the presence of LC in the polymer matrix hinders the growth of PP crystals. This effect seems to be more prominent for the FD-LC filler obtained from the more dilute solution, again confirming their better dispersion in PP. Moreover, the higher temperature annealed FD-LC addition further reduces the crystallization activation energy and help the crystallization system.

\section{Conclusions}

In this work, freeze-dried alkali lignin was annealed and used as carbon filler to enhance the mechanical and thermal properties of polypropylene. It is found that the freeze-dried lignin can maintain its morphology after carbonization, exhibiting a nanosize thin mesh or sheet-like morphology, and the thickness decreases with the reduced concentration of lignin solution. The obtained FD-LCs can be easily broken into small pieces by melt compounding with PP, giving the corresponding PP/FD-LC composites more uniform filler dispersion and much larger interfacial area than their counterpart with AR-LC. The results of tensile mechanical tests show that the Young's modulus and elongation at break of the $\mathrm{PP} / \mathrm{LC}$ composites are improved by using the FD-LCs as additive in comparison with those of neat PP or PP with the same amount of AR-LC. Also, it reveals the significant toughness effect of low temperature annealed FD-LC in PP matrix. Moreover, the annealing temperature greatly affects the component and the SSA of the resultant carbon, addition of the higher temperature annealed FD-LC results in the further enhancement of modulus but drop of elongation at break. In conclusion, it is demonstrated that freeze-drying is 
a simple and efficient method to develop low cost and renewable carbon fillers for polyolefin.

\section{Conflicts of interest}

There are no conflicts to declare.

\section{Acknowledgements}

This work was supported by the National Natural Science Foundation of China (51303206, 21275021), Scientific and Technological Research Program of Chongqing Municipal Education Commission (KJ1601209, KJ1712311).

\section{References}

1 F. G. Calvo-Flores and J. A. Dobado, ChemSusChem, 2010, 3, 1227-1235.

2 G. Gellerstedt, Ind. Crops Prod., 2015, 77, 845-854.

3 M. Norgren and H. Edlund, Curr. Opin. Colloid Interface Sci., 2014, 19, 409-416.

4 V. K. Thakur, M. K. Thakur, P. Raghavan and M. R. Kessler, ACS Sustainable Chem. Eng., 2014, 2, 1072-1092.

5 S. Gillet, M. Aguedo, L. Petitjean, A. R. C. Morais, A. M. da Costa Lopes, R. M. Lukasik and P. T. Anastas, Green Chem., 2017, 19, 4200-4233.

6 D. Tian, J. Hu, J. Bao, R. P. Chandra, J. N. Saddler and C. Lu, Biotechnol. Biofuels, 2017, 10, 192.

7 T. Saito, R. H. Brown, M. A. Hunt, D. L. Pickel, J. M. Pickel, J. M. Messman, F. S. Baker, M. Keller and A. K. Naskar, Green Chem., 2012, 14, 3295-3303.

8 X. Wang, C. Jiang, B. Hou, Y. Wang, C. Hao and J. Wu, Chemosphere, 2018, 206, 587-596.

9 X. Guo, S. Zhang and X. Q. Shan, J. Hazard. Mater., 2008, 151, 134-142.

10 J. Dörrstein, R. Scholz, D. Schwarz, D. Schieder, V. Sieber, F. Walther and C. Zollfrank, Compos. Struct., 2018, 189, 349-356.

11 D. Kun and B. Pukánszky, Eur. Polym. J., 2017, 93, 618-641.

12 Y. Sun, L. Yang, X. Lu and C. He, J. Mater. Chem. A, 2015, 3, 3699-3709.

13 C. D. Tran, J. Chen, J. K. Keum and A. K. Naskar, Adv. Funct. Mater., 2016, 26, 2677-2685.

14 D. Kai, H. M. Chong, L. P. Chow, L. Jiang, Q. Lin, K. Zhang, H. Zhang, Z. Zhang and X. J. Loh, Compos. Sci. Technol., 2018, 158, 26-33.
15 M. Martin-Martinez, M. F. F. Barreiro, A. M. T. Silva, J. L. Figueiredo, J. L. Faria and H. T. Gomes, Appl. Catal., $B, 2017,219,372-378$.

16 X.-F. Li, Q. Xu, Y. Fu and Q.-X. Guo, Environ. Prog. Sustainable Energy, 2014, 33, 519-526.

17 A. Oroumei, B. Fox and M. Naebe, ACS Sustainable Chem. Eng., 2015, 3, 758-769.

18 S. Chatterjee, E. B. Jones, A. C. Clingenpeel, A. M. McKenna, O. Rios, N. W. McNutt, D. J. Keffer and A. Johs, ACS Sustainable Chem. Eng., 2014, 2, 2002-2010.

19 S. Chatterjee, A. Clingenpeel, A. McKenna, O. Rios and A. Johs, $R S C$ Adv., 2014, 4, 4743-4753.

20 M.-Y. Chen, Y.-B. Huang, H. Pang, X.-X. Liu and Y. Fu, Green Chem., 2015, 17, 1710-1717.

21 X. Xu, J. Zhou, D. H. Nagaraju, L. Jiang, V. R. Marinov, G. Lubineau, H. N. Alshareef and M. Oh, Adv. Funct. Mater., 2015, 25, 3193-3202.

22 Z. Starý and J. Krückel, Polymer, 2018, 139, 52-59.

23 E. A. M. Hassan, D. Ge, L. Yang, J. Zhou, M. Liu, M. Yu and S. Zhu, Composites, Part A, 2018, 112, 155-160.

24 S. R. Yearla and K. Padmasree, J. Exp. Nanosci., 2015, 11, 289-302.

25 H. Sun, Z. Xu and C. Gao, Adv. Mater., 2013, 25, 2554-2560.

26 F. He, C. Sui, X. He and M. Li, Mater. Lett., 2015, 152, 9-12.

27 H. Hu, Z. Zhao, W. Wan, Y. Gogotsi and J. Qiu, Adv. Mater., 2013, 25, 2219-2223.

28 S. Kitajima and Y. Tominaga, Ionics, 2012, 18, 845-851.

29 F. Chen, W. Liu, S. I. Seyed Shahabadi, J. Xu and X. Lu, ACS Sustainable Chem. Eng., 2016, 4, 4997-5004.

30 T. Ramanathan, A. A. Abdala, S. Stankovich, D. A. Dikin, M. Herrera-Alonso, R. D. Piner, D. H. Adamson, H. C. Schniepp, X. Chen, R. S. Ruoff, S. T. Nguyen, I. A. Aksay, R. K. Prud'Homme and L. C. Brinson, Nat. Nanotechnol., 2008, 3, 327-331.

$31 \mathrm{X} . \mathrm{Xu}$, J. Zhou, L. Jiang, G. Lubineau, S. A. Payne and D. Gutschmidt, Carbon, 2014, 80, 91-102.

32 B. Bozsódi, V. Romhányi, P. Pataki, D. Kun, K. Renner and B. Pukánszky, Mater. Des., 2016, 103, 32-39.

33 K. Bula, Ł. Klapiszewski and T. Jesionowski, Polym. Compos., 2015, 36, 913-922.

34 W. Liu, R. Zhou, H. L. S. Goh, S. Huang and X. Lu, ACS Appl. Mater. Interfaces, 2014, 6, 5810-5817.

35 S. Borysiak, Ł. Klapiszewski, K. Bula and T. Jesionowski, J. Therm. Anal. Calorim., 2016, 126, 251-262. 